الأخطاء الثائعة في كتابة الحروف العربية لدى الطلاب في قسم تعليم اللغة العربية

\title{
تعليم المفردات العربية للأطفال بالطريقة الأغنية في روضة الأطفال " الأسوة "
}

\section{ديلنجو كلاتين}

Anisatul Barokah

nisekapoor@yahoo.com

Institut Agama Islam Negeri Surakarta

تهدف هذه الدراسة إلى الحصول على صورة شاملة حول نموذج التعلم المفردات العربية بالطريقة الأغتية في روضة الأطفال "الأسوة" دلغو كلاتين. بوصف واضح، تأمل الباحثة إنتاج معلومات كاملة ودقيقة حول تعلم المفردات في المستوى الأساسي الذي سيساعد بالتأكيد الممارسين والمراقبون العرب في تطوير نماذج تعلم اللغة العربية للاطفال. في النهاية ، تهدف نتائج هذه الدراسة لتشجيع الابتكار الجديد في مجال تعليم اللغة العبية أطفال الاندونيسيين من خلال الموضوعات ووسائل الإعلام وتقنيات التعلم وما إلى ذلك. الأطفال الذين يجلسون في روضة الأطفال ومعظمهم لم يقدروا على قراءة النص بشكل جيد .لذلك هناك مرحلة ضرورية تميز في

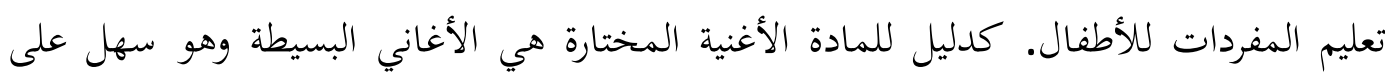

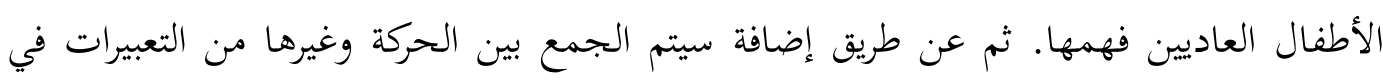

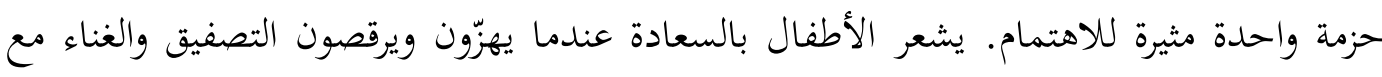
شخص ما يثقون به ويحبونه. حتى عندما يشعرون بالسعادة والترفيه، تساعد الموسيقى تكوين المهارات العقلية والعاطفية والاجتماعية والبدنية هم بالإضافة إلى منحهم الإثارة والمهارات بحاجة للبدء في التعلم بشكل مستقل. الكلمات الائيسية: المفردات، الطريقة الأغنية

المقدمة

اللغة العربية هي واحدة من اللغات الأجنبية التي يتعلمها العديد من الإندونيسيين. لذلك، من الضروري تعلم اللغة العربية مناسب للأشخاص غير العرب. تعلم اللغات الأجنبية في هذه الحالة يمكن أن يتم العربية بطرق وأساليب مختلفة. وبالمثل مع تعلم المفردات. 
و من المشاكل الأساسية في تعلم اللغة العربية هو إثراء المفردات. يجب أن يتم تصميم

تعلم اللغة العربية للمبتدئين، وخاصة للأطفال غير العرب، بشكل شامل من خلال وضع معايير الكفاءة اللغوية الواضحة. يجب أن يبدأ ذلك بعملية التعرف على اللغة العربية مثل: تعميق صياغة الحروف الهجائية وإيجاد التقاطعات بين مواد اللغة العربية وإتقان اللغة المحلية أو اللغة الأم التي كانت مملوكة. العادة أو التعويد هي أهم رأس مال في تعلم اللغة العربية المفردات من عناصر اللغة التي يجب أن تكون مملوكة للمتعلمين من اللغات الأجنبية وكذلك اللغة العربية. يمكن لمفردات مناسبة باللغة العربية أن تدعم الشخص في التواصل والكتابة بتلك اللغة. وبالتالي ، يمكن القول أن التحدث والكتابة، أي الكفاءة اللغوية لا يمكن نجاحها بدون المفردات، يجب أن تكون مدعومة بالمعرفة والإتقان الثري، والإنتاجي والمفردات الفعلية. تعتبر إضافة مفردات الشخص بشكل عام جزءًا مهمًا، سواء من عملية تعلم اللغة أو تطوير قدرات الشخص في لغة تم إتقانها. غالبًا ما يتعلم طلاب المدارس كلمات جديدة كجزء من موضوعات معينة والعديد من البالغين يعتبرون تكوين المفردات نشاطًا تعليميًا ومثيرًا للاهتمام. لذلك، هناك حاجة إلى الطريقة الصحيحة لتعلم المفردات العربية بحيث يمكن تحقيق الحاجة إلى المفردات في تعلم اللغة العربية.

يجب أن يتم تصميم تعلم اللغة العربية للمبتدئين، وخاصة للأطفال غير العرب، بشكل شامل من خلال وضع معايير الكفاءة اللغوية الواضحة. أي أن الدراسة تبدأ بعملية إدخال اللغة العربية مثل: تعميق صياغة الحروف الهجائية وإيجاد التقاطعات بين مواد اللغة العربية وإتقان اللغة المحلية أو اللغة الأم التي لدى الطلاب. العادة أو التعويد هي أهم رأس مال في تعلم اللغة.(علي الحديدي: 128) 
من ناحية أخرى، فإن نموذج التعلم العربي على مستوى المبتدئين، مثل المدرسة الإبتدائية، شعر أقل جاذبية للطلاب، وحتى جعلهم يعانون من الصدمة في اللغة العربية التي اعتبرت أنها صعبة. لذلك كان البحث عن برنامج عرب غينة وتطويره ضرورة. يجب تعديل استيعاب عنصر اللغة مع لغة الطفل. إن المشاركة التفاعلية للمعلمين والطلاب من خلال التواصل المكثف ستجعل عملية نقل اللغة جذابة. وهذا ما يحتاجه الأطفال في المراحل الأولى من اكتساب اللغات الأجنبية.

المفردات هي إتقان لغة داعمة يجب أن يمتلكها المتعلمون، بالإضافة إلى أربع مهارات لغوية أخرى، وهي الاستماع والتحدث والقراءة والكتابة. يجب أن تتقن المفردات باللغة العربية لأن المفردات تؤثر على قدرة الشخص على التواصل شفهيا وكتابيا. من هذا المنطلق، تهتم الباحثة بالبحث في إتقان المفردات، لأنه على الرغم من أن إتقان المفردات هو مؤيد للمهارات اللغوية، فإن إتقان المفردات أمر مهم حتى يمكن إتقان المهارات اللغوية الأربعة بشكل جيد. وبالتالي من الواضح أن إتقان المفردات له تأثير مهم في إتقان اللغة. ولإضفاء مزيد من الجاذبية على الأطفال وتطوير اهتمامهم ومواهبهم، أضاف برنامج تعليم اللغة العربية بالغناء. أكثر من ذلك، عندما عرف الأطفال الأغاني من قبل، ستكون عملية التعلم أسهل وأكثر فاعلية. ستكون الأغاني مثيرة للغاية عندما تساعد في التعبير الذي يدعم معنى الكلمات في الأغنية. يمكن للطفل اللعب بحرية مع الكلمات والأصوات الأخرى، وتطوير

المهارات اللغوية بطريقة ممتعة بشكل طبيعي.(Don Campbell 2002:130)

كثير من البحوث السابقة تبحث عن التعليم في العصر الذهبي حول اكتساب اللغة .كما بحثت سائدة رمضان، عن الاستراتيجيات المستخدمة للمعلم أو المدرسة، وكذلك المسائل التي 
تؤثر على الزراعة الأولى من تعليم اللغة العربية .وجدت هذه الدراسة أن الإستراتيجية المستخدمة في تعليم اللغة العربية في مرحلة الطفولة المبكرة هي استخدام إستراتيجيات المفردات .تدرس Early literacy research with البحوث الآخرين من خلال زيتي (2010) دراسة بعنوان children speaking German as an additional language تطور عملية تعليم اللغة لأطفال المهاجرين الذين أتقنوا أن اللغة الأولى وتعليم اللغة الألمانية كلغة ثانية. بحث أخر هو بحث حواء (2014)، حاولت التعرف على التطور اللغوي للطفل خلال مرحلة الطفولة المبكرة 5-6 سنوات من العمر في منطقة جنوب سيكربيلا ماتارام .في حين ركزت هذه الدراسة على السيطرة على المفردات العربية للطفولة المبكرة التي تعاني من العصر الذهبي ، وركزت على تدريس المفردات من خلال الأغاني. من هذا المنطلق تحاول الباحثة دراسة كيفية حصول الأطفال في عصرهم الذهبي على تعليم المفردات العربية ، مما يؤثر كثيرا على استعداد الأطفال لتعلم اللغة العربية عند دخولهم سن التعليم الابتدائي. و أساسا علي أهمية تعليم المفردات للأطفال،أقامت الباحثة بالموضوع تعليم المفردات العربية للأطفال بالطريقة الأغنية في روضة الأطفال " الأسوة " ديلنجو كلاتين لمعرفة كيفية تطبيق تعليم المفردات للأطفال بالطريقة الأغنية.

إن المفردات عنصور من عناصر اللغة الهامة بحيث يتضمن عليها المعانى واستخدام في اللغة من المتكلم نفسه أو من الكاتب، والشخض تزدادله مهاراته في اللغة إذا ازدادت مفرداته. لأن كفاءة مهارة لغة الشخص متوقف على المفردات التي استوعب معانيها اللفطية ( Handri Guntur Tariga.1990:2). إن المفردات هي أدوات حمل المعنى كما أنها في وقت آخر 
كوسيلة للتفكير. لأن المتكلم يستطيع أن يفكر ثم يعبر ما خطر في باله و فكره بكلمات ما يريد. والمفردات إحدى العناصر اللغوية الّتي ينبغي على تعلم اللّغة العربيّة من الأجانب تعلمها ليحصل على الكفاءة اللغوية المرغوبة.

المفردات كما ذكرت في القاموس الإنجيليزية - الإندونيسية ألفها إيخول و شاذلي هي

Jhon 1998:2) vocabulary قائمة الكلمات و المفردات. و في اللغة الإنجيليزية سميت ب Echol). في اصطلاح القاموس الإندونسية عند بالاي فوستاكا هي قائمة الكلمات. المفردات واحدها مفردة. و هي اللفظ أو الكلمة التي تتكون من حرفين فأكثر و تدل على معنى، سواء كانت فعلا أم اسما أم أدات (ناصر عبد الله الغالى و عبد الحميد عبد الله.دون السنة: 78). المفردات أو الكلمات هي الوحدات التي تترتب أفقيا وفقا نظام نحوي خاص لتكوين الجملة. فهي بذلك أصغر وحدة لغوية حرة، و هي تختلف عن الصوت الذي هي أصغر وحدة لغوية ذات معنى أيضا، ولكنه قد يكون حرا أو غير حر. و هذا يعنى أن الكلمة قد تكون صوتا واحدا أو أكثرا. و المفردات في صطلاح القاموس العام للغة الأندونيسية هي قائمة الكلمات (Purwadaminta1995: 572). ويعرف المفردات بقائمة الكلمات مع القواعد، بها تتركب تركيبا و تتوحد في اللغة توحيدا (Yuni Pratiwi 1984:20).

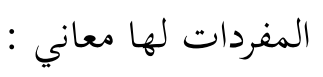
1. عنصور من عناصر اللغة الشاملة على المعارف عن المعانى واستخدمها في اللغة. 2. - الكلمات التي يستوعب عليها المتكلم والكاتب،

3. قائمة المكلمات المنظمة مع البيان الموخز مثل القاموس Kridalaksana 1982

(Harimakti 
عند هورن، المفردات هي جمع من كلمات لشكل اللغة. دور المفردات هي أمر مهم

لترقية أربع مهارات اللغة، كما قال فليت أن قدرة الطلاب لفهم أربع مهارات اللغة توقف على كفائة المفردات الذي تملك بهم.

المفردات واحدها مفردة وتقصد بها: اللفظة أو الكلمة التي تتكون من حرفين فأكثر و تدل على معنى سواء كانت فعلا أم اسما أم أداة (سيف المصطفي, 2011:61). أنواع المفردات

هناك عدة تقسيمات للمفردات منها: (رشدي أحمد طعيمة 216-218) 1 أ. مردات للفهم، وهذه تنقسم إلى نوعين :

(1) الاستماع ويقصد بذلك مجموع الكلمات التى يستطيع الفرد التعرف عليها وفهمها عندما يتلقاها من أحد المتحدثين.

القراءة ويقصد بذلك مجموع الكلمات التى يستطيع الفرد التعرف عليها وفهمها

$$
\text { عندما يتصل بها على صفحة مطبوعة. }
$$$$
\text { ب. مفردات للكلام، وهذه أيضا تنقسم إلى نوعين: }
$$

عادية، ويقصد بها مجموع الكلمات التى يستخدمها الفرد في حياته اليومية.

(2) موقيفية، ويقصد بها مجموع الكلمات التى يحتفظ بها الفرد ولا يستخدمها إلا

$$
\begin{aligned}
& \text { ج. مفردات للكتابة، وهذه أيضا تنقسم إلى نوعين: معين أو عندما تكن له مناسبة. }
\end{aligned}
$$


عادية ويقصد بها مجموع الكلمات التى يستخدمها الفرد في مواقف الاتصال

$$
\text { الكتابي الشخصى مثل أخذ مذكرات، كتابة يوميات... الخ. }
$$

موقفية ويقصد بها مجموع الكلمات التى يستخدمها الفرد في مواقف الاتصال

$$
\begin{aligned}
\text { د. مفردات كامنة، وتنقسم كذلك إلى نوعين : الكتابي الرسمى مثل تقديم طلب للعمل أو استقالة أو كتابة تقرير ....الخ }
\end{aligned}
$$

سياقية، ويقصد بها مجموع الكلمات التى يمكن تفسيرها من السياق الذى

$$
\text { وردت فيه. }
$$

تحليلية، و يقصد بها مجموع الكلمات التى يمكن تفسيرها استنادا إلى

خصائصها الصرفية كأن نرى ما زيد عليها من حروف أو ما نقص، أو في ضوء

$$
\begin{aligned}
& \text { الإلمام بلغات أخرى } \\
& \text { 2. تقسيمها حسب المعنى، وهي : }
\end{aligned}
$$

أ) كلمات المحتوى، ويقصد بها مجموع المفردات الأساسية التى تشكل صلب

$$
\text { الرسالة مثل الأسماء والأفعال....الخ. }
$$

ب) كلمات وظيفية، ويقصد بها مجموع المفردات التى تربط المفردات والجمل التى يستعان بها على إتمام الرسالة مثل حروف الجر والعطف وأدوات الإستفهام وأدوات الربط

$$
\text { بشكل عام. }
$$

ج) كلمات و عنتودية، ويقصد بها مجموع المفردات التى لا تنقل معنى معينا وهى مستقلة بذاتها وإنما تحتاج إلى كلمات أخرى مساعدة تنقل من خلالها إلى المستقبل 
معنى خاصا مثل (رغب) فهذه الكلمة تكون بمعنى أحب في قولنا: رغب في وتكون

$$
\text { بمعنى انصرف في قولنا: رغب عن. }
$$

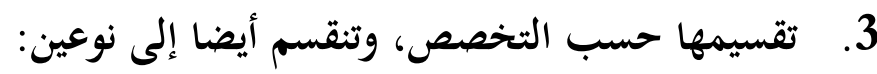

كلمات خادمة، ويقصد بها مجموع الكلمات العامة التى يستخدمها الفرد في

$$
\text { مواقف الحياة العادية أو استخداماته الرسمية غير التخصصية. }
$$

ب) كلمات تخصصية، ويقصد بها مجموع الكلمات التى تنقل معانى خاصة أو تستخدم بكثرة في مجال معين. وتسمى أيضا بالكلمات المحلية والكلمات الاستخدامية

\section{4. تقسيمها حسب الاستخدام، وهي نوعان:}

كلمات نشيطة ، و يقصد بها مجموع المفردات التى يكثر الفرد من استعمالها

في الكلام أو الكتابة أو حتى يسمعها أو يقرؤها بكثرة.

ب) كلمات خاملة، ويقصد بها مجموع الكلمات التى يحتفظ الفرد بها في رصيدة اللغوى وإن لم يستعملها. وهذا النوع من المفردات التي يفهم الفرد دلالاته واستخداماته

$$
\text { عندما يظهر له على الصفحة المطبوعة أو يصل إلى سمعه. }
$$

و قال ناصر عبدالله الغال و عبد الحميد عبدالله أن المفردات العربية تتضمن أنواع وهي (اتحاد مدرسى

$$
\text { اللغة العربية بإندونيسيا، دور اللغة العربية، 2011: 711-712): }
$$

1) مفردات اسمية و تشمل: الاسم العام والعلم والمصدر (رجل-محمد-كتابة)، الصفة

$$
\text { (طويل-مصرى-احسن-اعلم)، الضمير (أنا-هذه-التى) }
$$


2) مفردات فعلية و تشمل: الفعل المضي (طلع) والفعل المضارع (يكتب) والفعل الأمر

$$
\text { 3) مفردات الظروف ويتنوع الى: ظروف الزمن (امس) ظروف المكان (فوق) }
$$

4) الادوات وتشمل: الروابط مثل حروف الجر، وحروف العطف، وحروف الإستثناء

$$
\text { والاستدراك. }
$$

$$
\text { التحويليات وتشمل أدوات النفي وادوات الإستفهام. }
$$

6) الخوف الف: وسميت بذالك لمخالفتها من كل ما ذكر وتنقسم الى:

$$
\text { 1. 1. اسماء الأفعال }
$$

$$
\text { 3. المدح و الذم (نعم، وبئس) }
$$

$$
\text { 4. العجب (ما أفعله وأفعل به) }
$$

$$
\text { أساليب شرح المفردات (عبد الرحمن إبراهيم الفوزان 1432:5) }
$$

- بيان ما تدلّ عليه الكلمة بإبراز عينها أو صورتها إن كانت محسوسة

$$
\begin{aligned}
& \text { - } \\
& \text { - } \\
& \text { - ذ ذكر المتضادات } \\
& \text { - تداعي المعاني } \\
& \text { - ذكر أصل الكلمة ومشتقا } \\
& \text { - شرح معنى الكلمة بالعربيّة }
\end{aligned}
$$


- إعادة القراءة وتعدّدها يساعد على معرفة المعنى أكثر

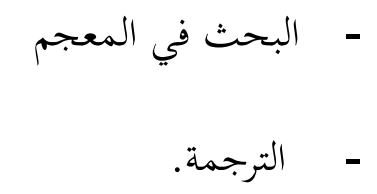

\section{تعليم المفردات بالطريقة الأغنية}

التعليم

التعليم هو مساعدة التلاميذ لإنماء قواهم العقلية والخلقية وتنظيمها حتى يتحلوا

بالأخلاق الكريمة ويستعدوا لمستقبلهم .والتعليم أيضا هو عملية يمارسها الفرد لتغيير سلوكه

(سوترسنو أحمد. 2001:1). مهم للباحثة أن يؤكد مفهوم تعليم المفردات لأنه قد يخطئ البعض

في فهم تعليم المفردات على أنه هو التعليم الدارس الأجنبى معنى كلمة عربية يعني قدرته على

ترجمه الكلمة إلى لغته و إيجاد مقابل لها .و البعض الآخر يظن أن تعليم الكلمة العببية يعني

قدرة الدارس على تحديد معناها في القوامس والمعاجم العربية ـكلا، ليس هذا المراد من مفهوم تعليم المفردات.

أما تعليم المفردات هو توجيه الطلاب لأن تكون لديهم القدرة على نطق حروف

المفردات و فهم معناها ومعرفة طرقة الإشتقاق منها ووصفها في تركيب لغوي صحيح والقدرة على استخدام الكلمات المناسبة في المكان المناسب (رشدي أحمد طعيمة 19). تعليم المفردات أو الكلمة العربية للتلاميذ الأجانب هو أن يكون التلميذ قادرا على ترجمة الكلمة و تحديد معنى المفردات ونطقها السليم، و كذلك قدر استخدام الكلمة المناسبة في سياق الجملة السليم، لأنه لا يفيد كثيرا إذ حفظ التلميذ المفردات الكثيرة ولكن لم يقدر على استخدامها، وبالخاصة في حيات اليومية. 


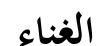

الغناء شيع مهمّ لتنميّة نفوس الأطفال، رسوندي (2004:13) في كتاب أستي (2007:32) أى أنّ الغناء للأطفال نشاط يستفيد فيه آلات الصّوت لزيادة الكلمات و المعارف عت الأشياء لا يعرفوها فى السآبق ـ هم سيتعلّمون كثيرا عن الكلمات الجدد، حتى يكونوا أغنياء بالكلمات الكثيرة و يستطيعوا أن يتكلمّوا يالكلمات المتنوّعة .أماّ عند متوندانج (1996:129) يقول الغناء نشاط ممتعة جداً وهذا العمل يستطيع أن ينبت الحماّسة للتّعلّم. بالغناء يحمّس الأطفال لأن يحبّوا أن يتعلّموا اللّغة العربيّة. بالغناء يشعر الطلاّب أحبّوا إلى أن يتعلّموا اللّغة العربيّة و أسهل لفهم اللغة العربية. بهذا العمل يهتمّ الطّلاب و يتّبوا الأشعار من هذا الغناء. أماّ رأي ويديا 2008:243) قالت أنّ الغناء نشاط موسيقيّ التّي تقديمه له شخصيّة لأنّه يستفيد آلات الموسيقيّ الموجودة في جسم الإنسان وله صفة مباشرة و ضروريّة بديعيّة. قال جمالوس 1975:11) أنّ الغناء له فنّ لتقديم الفكرة و الشّعور من نفوس الإنسان بالرّنين و الكلمات. مناسبا بذالك رأى أ ـت .محمود ( 1996) أنّ الغناء نشاط لتقديم الرّنين و الكلمات الّتي تشتمل على الإبداع(واحد مومي, 2008:10). الغناء له دور مهمّ لترقيّة تزويد المفردات على الطّّلَّ. كما قال علي أن هدف الغناء إعطاء شعورالحب و التّبديع و تغنيّة الكلمات و تمرين طاقة الذّكر و هو أيضا يعطى الفرح و السّرور و الحماّسة لأن يشعر الطلاب أن يتعلّموا اللّغة العربيّة أنشط. وسوف يتعلم الطلاب العديد من الكلمات الجديدة لإثراء المفردات و المهارة فى استخدامها. قال تنترا نور أندي (2008:31) أن أسلوب الغناء طريقة لقول الكلمات أو العبارات 
التّي سيأثر قضية أخرى، قال أنوار (2008:13) أن الكلمات أو العبارات التّي سيأثر قضية أخرى ، قال أسلوب الغناء سيساعد تعليم المفردات الّتي يستخدم الكلمات.

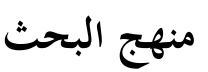

هذا البحث هو البحث الكيفي الوصفي. وقد أجري البحث في روضة الأطفال " الأسوة " ديلنجو كلاتين. يتم جمع البيانات عن طريق المقابلة والملاحظة والوثائق. لاختبار صدق البيانات باستخدام تثليث المصدر. وطريقة تحليلها بالنموذاج التفاعلي يتكون من جمع البيانات، حد البيانات، عرض البيانات، والاستنتاج. نتائج البحث

روضة الأطفال " الأسوة " هي مؤسسة تعليمية تدار من قبل مؤسسة تحت رعاية نهضة

العلماء، مع التركيز على التعليم الديني فيها ، روضة الأطفال " الأسوة " هي واحدة من المؤسسات التعليمية التي تطبق أسلوب الغناء في تعلم مفردات اللغة العربية. في حين أن سبب اختيار الباحث روضة الأطفال " الأسوة " هو أن هذه المدرسة تستخدم طريقة الغناء في مادة المفردات. إن استخدام أساليب الغناء في التعليم في مرحلة الطفولة المبكرة ليس غريباً على الأذنين، لأن هذه الطريقة مناسبة جداً لتحفيز الأطفال على امتصاص المادة التي يتم تدريسها، كما أن طريقة الغناء تؤثر بشكل كبير على الاهتمام التعليمي للأطفال، كما أنها تقضي على التوتر والتوتر . تشبع الطلاب عند القيام بأنشطة التعليم والتعلم.

من نتائج المقابلة مع الأستاذة نور العين، تم الحصول على بيانات أن خلفية استخدام أساليب الغناء في المدرسة لأن معظم الأطفال في المرحلة الأولى كانوا مولعين بالغناء. الغناء أكثر 
فعالية وكفاءة لأن الطلاب يفهمون ويحفظونه بشكل أسرع. وفقا لأستادة نور العين، ذكر أحد المعلمين أنه في التعليم الذي يستخدم اللغة العربية، فمن الضروري ممارسة مباشرة استخدام اللغة. هذا هو أكثر قدرة على تحفيز الطلاب ليكونوا قادرين على إتقان اللغة، ولكن يجب أن يكون لكل طالب مستوى مختلف من القدرة على استيعاب المواد التي تم تسليمها. استخدام المفردات عن طريق الغناء للطلاب مفيد جدا لهم لأنه يجعل من السهل تذكر وتلاوة المفردات التي تم تعلمها. الطريقة المستخدمة هي إعداد المعلم للمفردات مع الأغاني التي تكون فيها كل كلمة مفردات هي نفس الكلمة، ويقوم المدرس بكتابة المفردات على اللوحة ثم يقوم الطلاب بتسجيلها في كتبهم الخاصة ثم يقوم الطلاب بالاستماع إلى المعلم بقراءة المفردات، كما يقول المعلم الطلاب مرارا حفظ المفردات مع الأغنية. لن يتم تعظيم مستوى إتقان لغة أجنبية من سن مبكرة إذا لم تكن مناهج التعليم والتعلم، والأساليب والتقنيات المقدمة مناسبة. لهذه الطريقة يكون الاختيار مهمًا جدًا لتحقيق الأهداف التي تم تحديدها وتخطيطها. وبالمثل، يهدف تعلم المفردات بأغاني إلى مساعدة الطلاب على إثراء المفردات والمحادثة العربية في تعلم اللغة العربية هذا، طريقة واحدة يمكن استخدامها هي طريقة الغناء. و من خطوات تعليم المفردات بالطريقة الأغنية في روضة الأطفال " الأسوة " ديلانجو 
الأخطاء الشائعة فيكتابة الحروف العربية لدى الطلاب في قسم تعليم اللغة العربية

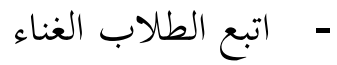

$$
\begin{aligned}
& \text { - - أنشد المعلم الغناء مرة أخرى } \\
& \text { - م استمع الطلاب على غناء المعلم } \\
& \text { - أشار المعلم الطلاب للغناء فى الأمام إلى آخره }
\end{aligned}
$$

مواصفات الغناء المستخدم في تعليم المفردات للمرحلة الطلابي

$$
\text { - - رنين الغناء من الأغنيّة المعروفة عندهم }
$$

- مصّ الغناء تتكوّن من المفردات الموجودة في كلّ وحدة لموضوع الغناء الواحد

- نصّ الغناء ليس فتط من العربيّة و ترجمته بل بطريقة متنوّعة مثلا بمضادّها أو

- - مرادفها أو تصريفها أو مفردها أو جمعها أو غيرها.

- نصّ الغناء يشتمل على الأسماء و الأفعال و الحروف.

- صوت الغناء من تسجيل صوت الباحثة نفسها أو مع صديقاتها أو طلابها و طبعا

$$
\text { بالموسيق. }
$$

\section{أمثلة الأغنية في تعليم المفردات}

مع طريقة الانضباط الذاتي، جعل عملية التعلم المتعة التي تثير في نهاية المطاف روح

التعلم للطلاب، والطلاب يمكن بسهولة حفظ الدروس. وقد ثبت ذلك من قبل الطلاب

المتحمسين في حفظ المكوّنات المعطاة، والحماسة في التعلم. هذا بسبب جودة المعلم و

الطريقة المستخدمة.

أما بالنسبة لأمثلة عن تعليم المفردات من خلال الغناء على النحو التالي:

الحيوانات (سونغ مثل أغنية Ya robbi bil mushthofa) 
الأخطاء الشائعلة في كتابة الحروف العببية للدى الطلاب في قسم تعليم اللغة العببية

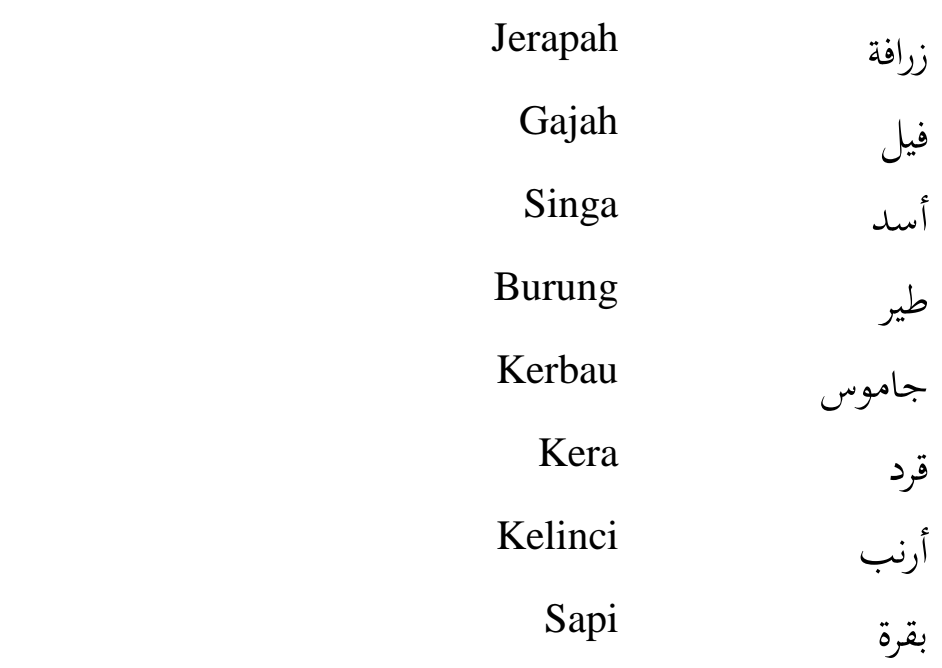

يا رب بالمصطفي بلغ مقاصدنا واغفر لنا ما مضي يا واسع الكرم

أعضاء الجسم (سونغ مثل أغنية Sholatulloh salamullah)

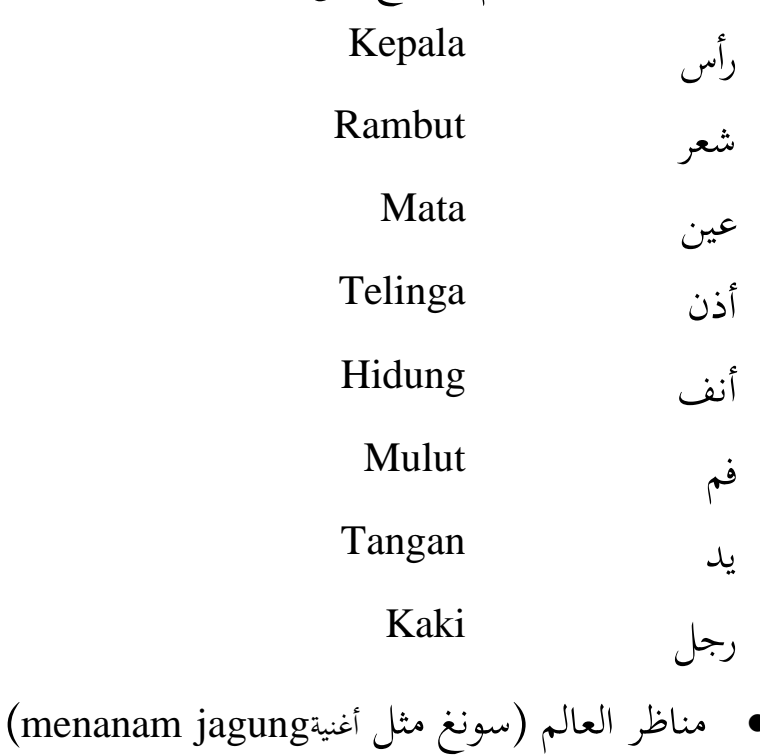

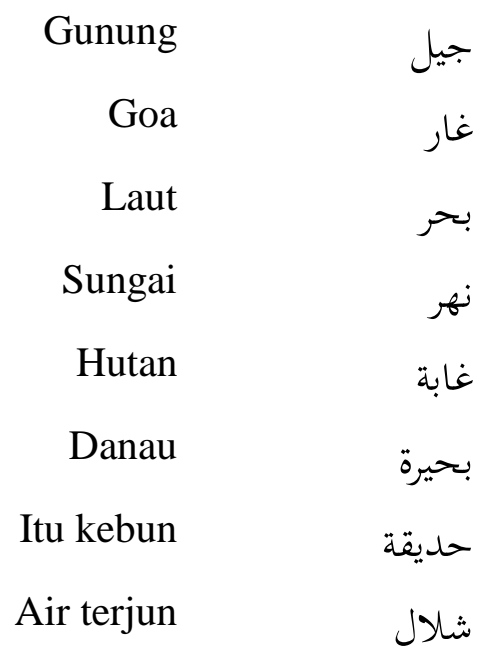


الأخطاء الثائعة في كتابة الحروف العربية لدى الطلاب في قسم تعليم اللغة العربية

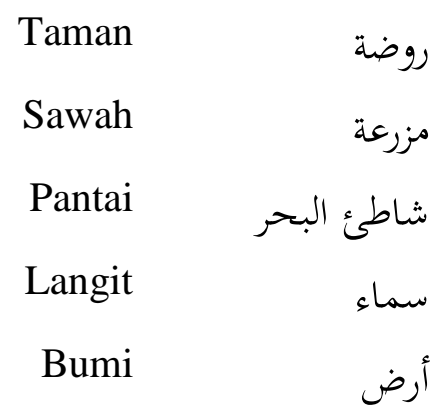

الأشياء في البيت (سونغ مثل أغنية menanam jagung)

Ayo kawan berbahasa Arab

Rumah بيت ، بيتي rumahku

باب pintu سقف، Atap

جدار Jendela نافذة dinding

بيت Rumah...rumah...rumah

السلام عليكم Jika kau masuk

بيت Rumah...rumah...rumah

السلام عليكم Jika kau masuk

خلاصة

يجب أن يتم تصميم تعلم اللغة العربية للمبتدئين، وخاصة للأطفال غير العرب، بشكل

شامل من خلال وضع معايير كفاءة اللغة. أي أن الدراسة تبدأ بعملية إدخال اللغة العربية مثل:

تعميق صياغة الحروف الهجائية وإيجاد التقاطعات بين مواد اللغة العربية وإتقان اللغة المحلية أو اللغة الأم التي لدى الطلاب. العادة (تعويد) هي أهم رأس مال في تعلم اللغة. 
تعتبر تعلم اللغة من خلال الأغنية واحدة من الحلول الصحيحة في عملية نقل اللغات

الأجنبية إلى اللغة الأولى التي يمتلكها الطلاب، إلى جانب أنشطة الغناء، مما يجعل جو التعلم منفصلاً عن التوتر حتى يتمكن الطفل من الحصول على لغة ثانية دون وعي وبشكل واضح.

من خلال الغناء، يتوقع من الطلاب والمعلمين أن يكونوا مترادفين ومرتاحين ومن المتوقع أن يكونوا بديلاً فوريًا (كيفية تقديم العلاج اللفظي) في عملية التعلم. سوف تعلم اللغة أثناء الغناء يساعد المفردات المتعلقة اكتساب اللغة للأطفال. الأشياء التي تحتاج إلى دراسة حول تنمية الأطفال الذين يتعلمون لغات أجنبية، واحدة منها هي اللغة والتواصل.

Press Idea : Yogyakarta.تحاد مدرسى اللغة العربية بإندونيسيا. (2011). دور اللغة العربية رشدي أحمد طعيمة. المرجع في تعليم اللغة العربية للناطقين بلغات أخرى. القسم الثاني (جامعة أم القرى معهد اللغة العربية وحدة البحوث والمناهج سلسلة دراسات في تعليم

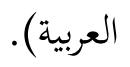$$
\text { رشلدي أحمد طعيمة ـ (919 1 ) . تعليم العربية لغير الناطقين هبا ـ مصر: الرياط. }
$$

سوترسنو أحمد. (2008). أصول التربية والتليم. معهد دار السلام : كونتور للتربية الإسلامية. عبد الرحمن إبراهيم الفوزان.(1432ه). إضاءات لمعلمى اللّغة العربيّة لغير الناطقين بها. الطبعة الأولى الرياض :فهرسة مكتبة الملك فهد الوطنية أثناء. علي الحديدي. مشككلات تعليم اللغة العببية لغير العرب. قاهرة مصر: دار الكاتب العربي. 


$$
\begin{aligned}
& \text { الأخطاء الشائعة فيكتابة الحروف العربية لدى الطلاب في قسم تعليم اللغة العربية } \\
& \text { محمود كامل الناقة.(1985). تعليم اللّغة العربيّة بلغات أخرى : أسسه- مداخله -طرق تلدريسه. } \\
& \text { مكة المكرمة : جامعة أم القرى. } \\
& \text { ناصر عبد الغالى و عبل حميد عبدالله.(1991). اسس إعداد الكتب التعليمية الغير الناطقين } \\
& \text { بالعربية. الرياض: دار الغالى. }
\end{aligned}
$$

Arikunto, Suharsimi, Prof. Dr. (1998). Prosedur Penelitian Suatu Pendekatan Praktek. Jakarta: Rineka Cipta.

Campbell, Don. (2002). Efek Mozart bagi Anak-anak. Jakarta: Gramedia Pustaka Utama. (Diindonesiakan oleh Alex Tri Kantjono Widodo)

Djajasudarma, T. Fatimah, Dr. (1993). Metode Linguistik Ancangan Metode Penelitian dan Kajian. Bandung: Eresco.

Echol, Jhon. (1998). Kamus Inggris Indonesia. Jakarta: PT Gramedia.

Harimakti, Kridalaksana. (1982). Kamus linguistic. Jakarta.: PT. Gramedia.

Murni, Wahid. (2008). Pengajaran Bahasa Sunda dengan metode Menyanyi. Program Pascasarjana

Mustofa, Saiful. Strategi Pembelajaran Bahasa Arab Inovatif. (2011). Uin Maliki Press

Pratiwi, Yuni. (1984). Penggunaan Nyanyian Sebagai Media Pengajaran Kosakat Siswa Kelas IV SD Sendang. Tulung agung : Jawa Timur.

Purwadaminta. (1995). Kamus Besar bahasa Indonesia. Jakarta: balai pustaka.

Tariga, Guntur, Handri. (1990). Pengertian kosakata: Jakarta.

\section{Internet:}

http://MaC'hSunbogspot.com/2013/08/strategi-pembelajaranmufradat.htmldiakses tanggal 10 Agustus 2018.

https://www.google.com/search?q=Maida+Dwi\%2C+Purwanti\%2C+Skripsi+Tah $\underline{\text { un}+2014 \% 2 \mathrm{C}+\text { hubungan+kemampuan+bahasa+anak+usia+dini+usia+5- }}$ $\underline{6+\text { tahun+dengan+pola+asuh+orang+tua+di+TK+Ad- }}$ Dinul+Qoyyim+Kapek+Bawah+Kecamatan+Gunungsari. Diakses tanggal 14 September 2018

https://www.google.com/search?q=Siti+Hawa\%2C+Skripsi+Tahun+2014\%2C+Id entifikasi+Perkembangan+Bahasa+Anak+Usia+Dini+Usia+5- 
الأخطاء الشائعة فيكتابة الحروف العربية لدى الطلاب في قسم تعليم اللغة العربية

$\underline{\text { 6+Tahun+Di+PAUD+Se-Kecamatan+Sekarbela+Mataram.Diakses }}$

tanggal 14 September 2018

https://www.google.com/search?q=STRATEGI+PEMBELAJARAN+BAHASA+

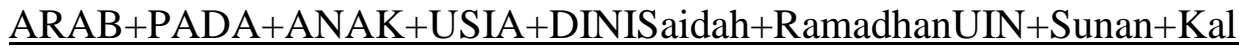
ijaga+Yogyakartasaidahramadhan. Diakses tanggal 14 September 2018 